\title{
Pulmonary function evaluation in type 2 diabetes mellitus patients submitted to metabolic surgery
}

\author{
Avaliação da função pulmonar em pacientes com diabetes \\ mellitus tipo 2 submetidos à cirurgia metabólica
}

Ariana de Melo Tosta, Marisa de Carvalho Borges, Élida Mara Carneiro da Silva, Tharsus Dias Takeuti, Júverson Alves Terra Júnior, Eduardo Crema*

Universidade Federal do Triângulo Mineiro (UFTM), Uberaba, MG, Brazil

\begin{abstract}
Introduction: Diabetes Mellitus (DM) is a multifactorial metabolic disorder. As considered a public health problem needing additional treatment options. Objective: This prospective study aimed at evaluating pulmonary function through spirometry, before and after metabolic surgery without gastric resection in type 2 DM patients. Methods: Sample was composed by 17 type 2 DM females. They were analyzed in pre (24 hours before surgical procedure), immediate post-operative period POST1 (24 hours after surgical procedure) and in the late postoperative period POST2 (two years after surgical procedure). Besides statistical analysis, it was evaluated the following spirometric parameters: forced vital capacity (FVC), forced expiratory volume in the first second (FEV1) and the FEV1 / FVC ratio (\%). Results: Spirometric parameters showed a value increase when compared PRE and POS2 values, except for FVC and FEV1, which was not statistically significant. Conclusion: Type 2 DM women submitted to metabolic surgery without gastric resection showed spirometric value
\end{abstract}

\footnotetext{
AMT: MS, e-mail: arianatosta@hotmail.com MCB: PhD, e-mail: marisaborges.uftm@gmail.com EMCS: PhD, email: elidamc16@gmail.com TDT: PhD, e-mail: tharsus.bio@hotmail.com JATJ: PhD, e-mail: juverson@terra.com.br EC: PhD, e-mail: cremauftm@mednet.com.br
} 
increased after two-year surgical procedure, when compared to preoperative period values. It is important additional studies about pulmonary function, diabetic patients and metabolic surgery without gastric resection.

Keywords: Diabetes Mellitus. Pulmonary Function. Surgery.

\section{Resumo}

Introdução: O Diabetes Mellitus (DM) é uma desordem metabólica multifatorial. Considerado um problema de saúde pública necessita de opções de tratamento adicionais. Objetivo: Este estudo prospectivo avaliou a função pulmonar, através da espirometria, antes e após a cirurgia metabólica sem ressecção gástrica em pacientes com diabetes mellitus tipo 2. Métodos: A amostra foi composta por 17 mulheres com diabetes mellitus tipo 2. Elas foram avaliadas no PRE (24 horas antes da cirurgia), pós-operatório imediato POST1 (24 horas após a cirurgia) e no pós-operatório tardio POST2 (dois anos após a cirurgia). Além da análise estatística, foram avaliados os seguintes parâmetros expirométricos: capacidade vital forçada (CVF), volume expiratório forçado no primeiro segundo (VEF1) e relação VEF1/CVF (\%). Resultados: os parâmetros expirométricos aumentaram quando comparados aos valores PRE e POS2, exceto para CVF e VEF1, os quais não foram estatisticamente significativos. Conclusão: Mulheres diabéticas tipo 2 que realizaram cirurgia metabólica sem ressecção gástrica aumentaram o valor expirométrico após dois anos do procedimento cirúrgico, quando comparadas aos valores no pré-operatório. Estudos adicionais são importantes sobre a função pulmonar, diabetes $e$ cirurgia metabólica sem ressecção gástrica.

Palavras-chave: Diabetes Mellitus, Função Pulmonar, Cirurgia

\section{Introduction}

Diabetes Mellitus (DM) is a multifactorial metabolic disorder characterized by chronic hyperglycemia due to secretion and / or action insulin defects, resulting in insulin resistance. High plasma glucose concentrations lead to chronic degeneration development associated to organ failure, especially eyes, kidneys, heart, nerves and blood vessels [1]. DM is considered a public health problem, mainly due to chronic complications, which often presenting a disabling character, by reducing quality of life and requiring expensive treatment of the health system [2 - 4].

At present, the world diabetic population is estimated to be about 387 million and can reach 471 million in 2035. Diabetic number is increasing due to population growth and aging, increased urbanization, the progressive obesity prevalence and sedentary lifestyle, as well as the greater DM patient survival being a prevalent disease in females [5 - 7].
There are several treatment options including a multidisciplinary clinical approach designed to promote weight loss, pharmacological therapies, and bariatric and metabolic surgical techniques $[8,9]$. The ileal transposition involves the segment removal of the distal ileum and its insertion into the proximal small intestine, a procedure that promoting early satiety and exerting benefits on glucose metabolism and weight loss. These effects probably can be attributed to incretins stimulation such as glucagon-like peptide-1 (GLP-1) and peptide YY (PYY), increasing insulin sensitivity in the short-and medium-term, allowing clinical type 2 DM patient control without the need for insulin or oral hypoglycemic agents [10 - 13].

This study aimed at evaluating pulmonary function through spirometry, by the following parameters: forced vital capacity (FVC), forced expiratory volume in the first second (FEV1) and the FEV1 / FVC ratio (\%) before and after metabolic surgery without gastric resection in type $2 \mathrm{DM}$ patients. 


\section{Methods}

A prospective study was conducted, performed by the Digestive Surgery discipline at Hospital das Clínicas (Universidade Federal do Triângulo Mineiro - UFTM, Brazil). Twenty female patients with type 2 diabetes mellitus, aged between 30 and 65 years (43.8) and body mass index (BMI) between 23 and $35 \mathrm{~kg} / \mathrm{m}^{2}$ (25.4) participated in this study. It was analyzed and approved by UFTM Research Ethics Committee (number 1264). Patient data were noted, in writing, and providing free consent after explanation.

Inclusion criteria were: type $2 \mathrm{DM}$ patients and metabolic surgery indication, age above 18 years, BMI between 23 and $35 \mathrm{~kg} / \mathrm{m}^{2}$, ability to understanding study purpose, ability to perform spirometry and consent informed in writing.

Exclusion criteria were: severe cardiopathy, neurological or cognitive deficits that made spirometry impossible, systemic diseases and respiratory infections and/or symptomatic allergic sinus disease, smokers or chronic obstructive pulmonary disease (COPD) patients, previous bronchial asthma diagnosis, pleuropulmonary abnormalities, thoracic deformities, liver cirrhosis suspicion or evidence, coagulopathy (platelet count below 50,000/ul), double medication in platelet antagonists (acetylsalicylic acid and clopidogrel), acute pancreatitis and jaundice, elevated surgical risk according to American Society of Anesthesiology (ASA) (ASA III and IV) (1963), and presented type 2 DM more than 10 years ago.

All patients were submitted to jejunal duodenal exclusion surgery with ileal segment interposition without gastric resection, which is constituted by an ileal segment interposition (approximately $100 \mathrm{~cm}$ ), which is transposed and anastomosed in the duodenum $2 \mathrm{~cm}$ from the pylorus and in the jejunum at $70 \mathrm{~cm}$ from the Treitz angle, thus excluding $100 \mathrm{~cm}$ from the duodeno-jejunal segment.

Patients were analyzed in pre (24 hours before surgical procedure), immediate post-operative period POST1 (24 hours after surgical procedure) and in the late postoperative period POST2 (two years after surgical procedure).
Pulmonary Function Evaluation

Spirometry was performed by a specialized professional, in the Pulmonary Function Laboratory of Pulmonology discipline at UFTM. A computerized spirometer (Master Screen PFT Jaeger) was used, and the examination was performed according to American Thoracic Society (ATS). The patients were instructed to remain in a comfortable, sitting position for 5 to 10 minutes before the test, and at the test time, they were instructed to keep their heads in a neutral and stable position. The procedure was explained and demonstrated, asking patients to inhale as deeply as possible and exhaled quickly into spirometer mouthpiece, thus preventing air leakage around the spirometer. The examination was performed three times at five-minute rest intervals, and the best values were noted for analyzing.

Pulmonary function evaluation through spirometry is one of the preoperative procedures often performed by UFTM patients Digestive Surgery Department, pulmonary functional alteration identification and quantification.

In this study, spirometry was performed in three different moments:

1) Pre-Operative (PRE), 24 hours before surgical procedure,

2) Post-Operative Immediate (POS1), 24 hours after surgical procedure

3) Late Post-Operative, 2 years after surgical procedure.

The evaluated parameters were: forced vital capacity (FVC) and forced expiratory volume in the first second (FEV1) and the FEV1 / FVC ratio (\%). The values obtained were expressed in liters / second and $\%$ predicted.

- Forced Vital Capacity (FVC): is one of the spirometric variables used to determining ventilatory changes. FVC is obtained through forced expiratory maneuver. It represents the maximum volume of exhaled air with maximum effort, from the maximum inspiration point. When it is below $80 \%$ of predicted, in normal FEV1 / FVC presence, it suggests a restrictive disorder. Confirmation 
can be made by measuring total pulmonary capacity (TPC), or radiologic findings compatible with restrictive disease associated to FVC reduction confirm the hypothesis.

- Forced Expiratory Volume in the First Second (FEV1): eliminated air amount in the first second at FVC maneuver. It is used to determine obstructive ventilatory disorders, by introduction of time measurements (one second) in the FVC maneuver. It basically evaluates obstructive disorders and when FVC is diminished by restrictive disorders it will decrease proportionally.

- FEV1 / FVC (\%): The ratio between these two measures is the one that best evaluates the obstructive disorders presence. The expected value for a given individual is derived from the chosen equation. For individuals up to 45 years the value of $75 \%$ or higher is expected. Below this value, the obstruction diagnosis is suggestive and should be defined through other values parallel analysis such as FEF25-75, FEV1 and other terminal flows.

\section{Statistical analysis}

Kolmogorov-Smirnov test was used to determine if the data were normally distributed. Parametric data were compared by Student's t-test and nonparametric data by the Wilcoxon test. Correlations were evaluated using the Pearson and Spearman correlation coefficients. Differences were considered significant when $\mathrm{p}<0.05$. Statistical analysis was performed using the Microsoft Excel 2010, GraphPad Prism 5.0 and SPSS 16.0 programs.

\section{Results}

\section{Forced Vital Capacity (FVC)}

Regarding the FVC values, a difference between the predicted values was $3.48(2.52-4.79)$ and the values obtained in the PRE 3.38 (2.16 - 4.99), but without statistical significance $(\mathrm{p}=0.12)$. There was a FVC values decrease at POS $2.63(1.88-4.42)(p=0.06)$. In POS 2, FVC 3.04 values (2.36 - 4.4) increased again, and approaching PRE values, but without statistical significance $(p=0.2)$ (Figure 1$)$.

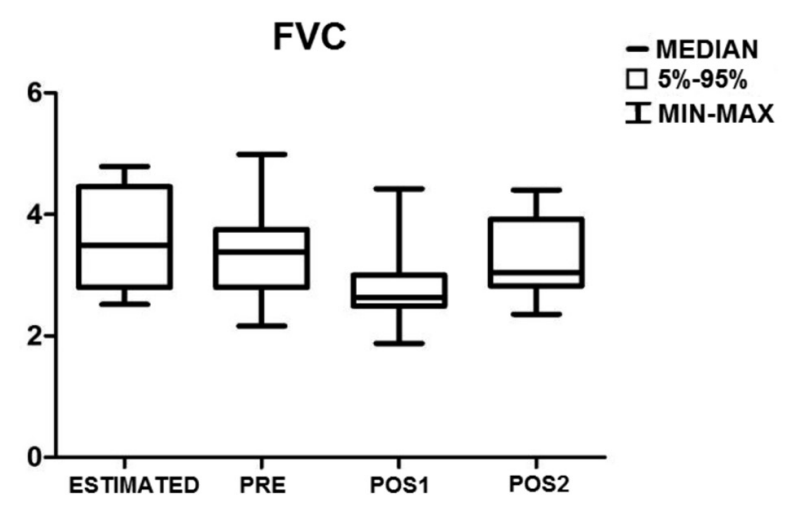

Note: Author data by Wilcoxon-Mann-Whitney nonparametric test with Bonferroni correction for multiple comparisons.

Figure 1 - Sample values predicted and obtained from the variable FVC in the preoperative period (PRE), in the immediate postoperative period (POS1) and in the late postoperative period (POS2).

Forced expiratory volume in the first second (FEV1)

There was a statistically significant difference between the predicted FEV1 2.81 values (2.07 - 3.81) and the PRE 2.52 values (1.76-3.64) ( $\mathrm{p}=0.04)$. Also, there was a non-significant drop in FEV1 values at POS1 2.06 (1.45 - 3.12) when compared to PRE values ( $p=0.04)$. At POS2, FEV1 valuesincreased again, 2.42 (1.96 - 3.22), close to values previously obtained in PRE, but without any statistical significance $(p=0.16)$ (Figure 2).

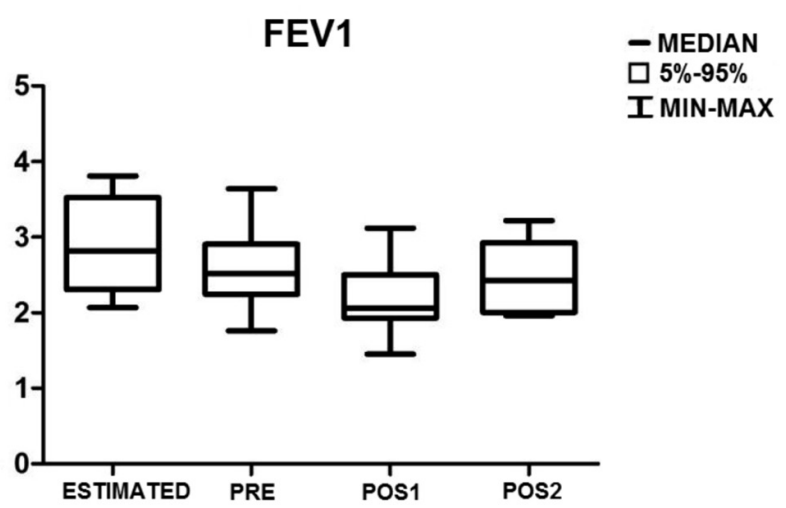

Note: Author data by Wilcoxon-Mann-Whitney nonparametric test with Bonferroni correction for multiple comparisons.

Figure 2 - Sample median of predicted and obtained FEV1 values in preoperative period (PRE), in the immediate postoperative period (POSI) and in the late postoperative period (POS2). 
FEV 1/FVC ratio (\%)

Regarding the FEV1/FVC (\%) values, a significant difference was observed between the predicted values 80.84 (77.15 - 83.49) and PRE 67.76 values (54.75 - 81.69), $\mathrm{p}=0.002$. There was an increase in FEV 1 / FVC (\%) in POS 73.22 (68.51 - 84.31), but without statistical significance, $\mathrm{p}=0.22$. In POS 2, FEV1 / FVC (\%) 69.66 values (52.07 - 86.86) presented a decrease when compared to POS1 values, these values approximated those obtained in PRE, but without statistical significance when compared with these, $p=0.38$ (Figure 3).

\section{FEV1/FVC(\%)}

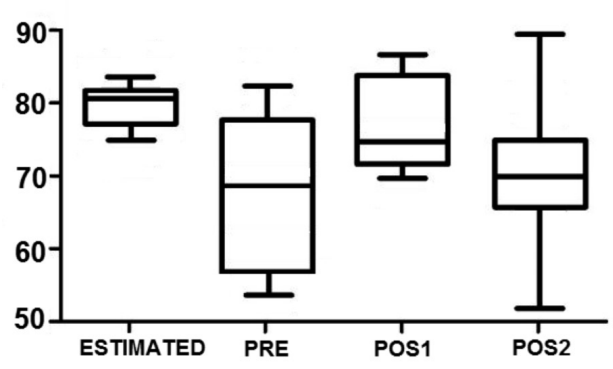

- MEDIAN

$\square 5 \%-95 \%$

I MIN-MAX

Note: * Significant $p$ values when $p<0.017$. Author data by Wilcoxon-Mann-Whitney non-parametric test with Bonferroni correction for multiple comparisons $(p=0.002)$.

Figure 3 - Sample median of predicted and obtained values of the FEVI/FVC variable (\%) in the preoperative period (PRE), in the immediate postoperative period (POSI) and in the late postoperative period (POS2).

\section{Discussion}

Abdomen surgical procedure, due to surgical trauma and anesthetic procedure, leads to pathophysiological in respiratory system changes. The following changes may be mentioned: pulmonary volumes and capacities reduction; respiratory muscle strength decreased; ventilation/perfusion ratio alteration, leading to pulmonary shunt elevation and ineffectiveness in defense mechanisms such as cough and immune system depression $[14,15]$.

Postoperative pulmonary function compromise in laparoscopic surgery is lower than in conventional surgery, suggesting a lower predisposition of these patients to the complication development [16]. But, laparoscopy can produce small changes, but they have pulmonary function impact [17].
Spirometry is a widely used pulmonary function test and describing obstruction effects or pulmonary function restriction. It plays a significant role in the early pulmonary damage diagnosis and its associated structures [18].

Pulmonary function may provide useful measures for systemic microangiopathy progression in diabetic patients. The basic concepts of normal pulmonary physiology that are involved in the pulmonary function test (spirometry) include mechanics (pulmonary tidal volume), ventilation-perfusion interrelation, diffusion and gas exchange, as well as respiratory muscle strength [19].

Pulmonary capacity reduction has been reported among diabetics. Diabetic patients demonstrated a significant FVC reduction [mean difference (95\%) - 0.36 $(-0.64,-0.07) P<0.01]$, forced expiratory volume in one second (VEF 1) $0.25(-0.50,-0.003) \mathrm{P}<0.04]$, and FVC $[-0.28(-0.54,-0.01) \mathrm{P}<0.04]$, in relation to nondiabetic controls.

Diabetic patients showed impaired pulmonary function independent of smoking. This reduced pulmonary function is likely to be a chronic DM complication [20 - 22].

In a study with 283 subjects (144 = diabetic, $139=$ non-diabetic), only FVC and FEV1 showed differences between groups because both variables were significantly lower in DM patients. The remaining spirometric variables did not present significant differences between the groups. Pulmonary function fall intensity with advancing age was similar between diabetic and non-diabetic subjects, with similar reductions in both groups [23].

We did not find studies that evaluated pulmonary function before and after metabolic surgery. Spirometric parameters analyzed in this study showed an increase in their values when PRE and POS2 values were compared, except for FVC and FEV1, which was not statistically significant. These results may be due to weight loss and glycemic control does not interfere in the pulmonary function alteration already installed. However, such control may allow the non-progression of this structural pulmonary dysfunction.

Surgical procedures interfere with pulmonary mechanics and tend to develop restrictive ventilatory changes, with FEV 1 and FVC reduction, which may reach a value of approximately 40 to $50 \%$ of the preoperative value and remaining reduced for at least one to two weeks. In most 
abdominal surgical procedures, these instabilities peak on the first postoperative day when the respiratory system becomes more vulnerable to postoperative pulmonary complications [24 - 26]. These alterations occur especially in operations in the upper abdomen and are mainly determined by diaphragmatic dysfunction, activated by surgical stimulation [27].

Several possibilities have been suggested to explain pulmonary volume decrease in abdominal surgery: pain, anesthesia, surgery time, surgical trauma, and others. However, nowadays, it is most accepted that this decrease is caused by diaphragmatic paresis, a reflex diaphragm inhibition consequence [28]. Sex is the single most important determinant of pulmonary function, accounting for $30 \%$ of its variation. In one study, the authors observed that in life-sustaining maneuvers women have a more thoracic ventilatory pattern than men, and that in men over 50 the ventilatory pattern becomes less thoracic. In the postoperative period, ventilation becomes more thoracic and less abdominal, mainly due to diaphragmatic dysfunction. This fact places women in greater advantage [29].

The pulmonary dysfunction detection by the physiotherapist can help in the surgical risk stratification [30]. So, it is important a multiprofessional follow-up in diabetic patient preparation who undergoes any abdominal surgery because, due to basic disease, can present previous pulmonary alterations, such as: decreased pulmonary function and respiratory muscle strength thus having a greater propensity for postoperative complications.

\section{Conclusion}

Despite being a limited study due to the relatively small sample, it was demonstrated that women with type 2 DM undergoing metabolic surgery without gastric resection showed increased spirometric values two years after the surgical procedure, when compared to preoperative period values. There is a need for additional studies in this area to further clarify the pulmonary involvement of patients with type $2 \mathrm{DM}$ submitted to metabolic surgery without gastric resection.

\section{Referências}

1. Lee E, Ryu GR, Ko SH, Ahn YB, Song KH. A role of pancreatic stellate cells in islet fibrosis and $\beta$-cell dysfunction in type 2 diabetes mellitus. Biochem Biophys Res Commun. 2017;485(2):328-34.

2. Meybodi HRA, Hasanzad M, Larijani B. Path to Personalized Medicine for Type 2 Diabetes Mellitus: Reality and Hope. Acta Med Iran. 2017;55(3):166-74.

3. Feng X, Astell-Burt T. Impact of a type 2 diabetes diagnosis on mental health, quality of life, and social contacts: a longitudinal study. BMJ Open Diabetes Res Care. 2017;5(1):e000198.

4. Miranda-Perez ME, Alarcon-Aguilar FJ, OrtegaCamarillo C, Escobar-Villanueva MC. Pancreatic $\beta$-Cells and Type 2 Diabetes Development. Curr Diabetes Rev. 2017;13(2):108-21.

5. Elrayah-Eliadarous $\mathrm{H}$, Östensson CG, Eltom $\mathrm{M}$, Johansson P, Sparring V, Wahlström R. Economic and social impact of diabetes mellitus in a low-income country: A case-control study in Sudan. J Diabetes. 2017. doi: 10.1111/1753-0407.12540. [Epub ahead of print]

6. Flor LS, Campos MR. The prevalence of diabetes mellitus and its associated factors in the Brazilian adult population: evidence from a population-based survey. Rev Bras Epidemiol. 2017;20(1):16-29.

7. Ogurtsova K, Fernandes JDR, Huang Y, Linnenkamp U, Guariguata L, Cho NH, et al. IDF Diabetes Atlas: Global estimates for the prevalence of diabetes for 2015 and 2040. Diabetes Res Clin Pract. 2017;128:40-50.

8. Syu YF, Inui A, Chen CY. A perspective on metabolic surgery from a gastroenterologist. J Pharmacol Sci. 2017;133(2):61-4.

9. Marahrens L, Röck D, Ziemssen T, Kern R, Ziemssen F, Fritsche A. [Implementation of the National Guidelines for the treatment of Diabetes mellitus type 2 in secondary diabetes centers]. Dtsch Med Wochenschr. 2017;142(18):e131-9.

10. Fernández-Soto ML, Martín-Leyva A, GonzálezJiménez A, García-Rubio J, Cózar-Ibáñez A, ZamoraCamacho FJ, et al. Remission of type 2 diabetes mellitus after bariatric surgery - comparison between procedures. Endokrynol Pol. 2017;68(1):18-25. 
11. Lee WJ, Aung L. Metabolic Surgery for Type 2 Diabetes Mellitus: Experience from Asia. Diabetes Metab J. 2016;40(6):433-43.

12. Chen W, Xu Q, Xiao Y, Zhou J, Zhang W, Lin G, et al. Blockade of Central GLP-1 Receptors Deteriorates the Improvement of Diabetes after Ileal Transposition. Int J Med Sci. 2016;13(12):955-62.

13. Previti E, Salinari S, Bertuzzi A, Capristo E, Bornstein S, Mingrone G. Glycemic control after metabolic surgery: a Granger causality and graph analysis. Am J Physiol Endocrinol Metab. 2017. doi: 10.1152/ ajpendo.00042.2017.

14. Fernandes SC, Santos RS, Giovanetti EA, Taniguchi C, Silva CS, Eid RA, et al. Impact of respiratory therapy in vital capacity and functionality of patients undergoing abdominal surgery. Einstein (Sao Paulo). 2016;14(2):202-7.

15. Agrelli TF, Ramos MC, Guglielminetti R, Silva AA, Crema E. Preoperative ambulatory inspiratory muscle training in patients undergoing esophagectomy. A pilot study. Int Surg. 2012;97(3):198-202.

16. Ciftci B, Aksoy M, Ince I, Ahıskalıoglu A, Ucar EY. The Effects of Positive End-Expiratory Pressure at Different Levels on Postoperative Respiration Parameters in Patients Undergoing Laparoscopic Cholecystectomy. J Invest Surg. 2017:1-7.

17. Sérvio TC, Pereira RSC, Cataneo DC. Study on functional cardiorespiratory changes after laparoscopic Nissen fundoplication. Acta Cir Bras. 2012;27 (7):499-504.

18. Meo SA. Significance of spirometry in diabetic patients. Int J Diabetes Mellit. 2010;2(1):47-50.

19. Aparna. Pulmonary function tests in type 2 diabetics and non-diabetic people -a comparative study. J Clin Diagn Res. 2013;7(8):1606-8.

20. Irfan M, Jabbar A, Haque AS, Awan S, Hussain SF. Pulmonary functions in patients with diabetes mellitus. Lung India. 2011;28(2):89-92.

21. Shah SH, Sonawane P, Nahar P, Vaidya S, Salvi S. Pulmonary function tests in type 2 diabetes mellitus and their association with glycemic control and duration of the disease. Lung India. 2013;30(2):108-12.

22. Klein OL, Kalhan R, Williams MV, Tipping M, Lee $\mathrm{J}$, Peng J, et al. Lung spirometry parameters and diffusion capacity are decreased in patients with Type 2 diabetes. Diabet Med. 2012;29(2):212-9.
23. Ortíz-Aguirre AR, Vargas MH, Torres-Cruz A, Quijano-Torres M. [Age related spirometric changes in diabetic patients]. Rev Invest Clin. 2006;58(2):109-18.

24. Grams ST, Ono LM, Noronha MA, Schivinski CI, Paulin E. Breathing exercises in upper abdominal surgery: a systematic review and meta-analysis. Rev Bras Fisioter. 2012;16(5):345-53.

25. Cleva Rd, Assumpção MS, Sasaya F, Chaves NZ, Santo MA, Fló C, et al. Correlation between intraabdominal pressure and pulmonary volumes after superior and inferior abdominal surgery. Clinics (São Paulo). 2014;69(7):483-6.

26. Bablekos GD, Michaelides SA, Analitis A, Charalabopoulos KA. Effects of laparoscopic cholecystectomy on lung function: a systematic review. World J Gastroenterol. 2014;20(46):17603-17.

27. Kumar AS, Alaparthi GK, Augustine AJ, Pazhyaottayil ZC, Ramakrishna A, Krishnakumar SK. Comparison of Flow and Volume Incentive Spirometry on Pulmonary Function and Exercise Tolerance in Open Abdominal Surgery: A Randomized Clinical Trial. J Clin Diagn Res. 2016;10(1):KC01-6.

28. Seo YK, Lee HJ, Ha TK, Lee KG. Effect of normal saline irrigation on attenuation of shoulder tip pain and on $\beta$-endorphin levels after laparoscopic cholecystectomy. J Laparoendosc Adv Surg Tech A. 2012;22(4):311-4.

29. Tunkamnerdthai O, Auvichayapat P, Donsom M, Leelayuwat N. Improvement of pulmonary function with arm swing exercise in patients with type 2 diabetes. J Phys Ther Sci. 2015;27(3):649-54.

30. Soares SM, Nucci LB, Silva MM, Campacci TC. Pulmonary function and physical performance outcomes with preoperative physical therapy in upper abdominal surgery: a randomized controlled trial. Clin Rehabil. 2013;27(7):616-27.

Received in 09/27/2017

Recebido em 27/09/2017

Approved in 11/07/2017

Aprovado em 07/11/2017 